\title{
La "eroticidad" de la Mapu: poética-política de recuperación territorial en Roxana Miranda Rupailaf y el video-poema $E l$ Shumpall ${ }^{1}$
}

\author{
"Eroticism" of the Mapu: Poetics and Politics of Land Recovery \\ in the Work of Roxana Miranda Rupailaf and the Video-Poem El \\ Shumpall
}

\author{
Montserrat Madariaga Caro \\ Universidad de Texas, Austin \\ montserratmadariaga@utexas.edu
}

Resumen: Las relaciones entre vidas humanas y no humanas se han abordado ampliamente desde el pensamiento Mapuche (Calfío, Curivil, Pichinao, entre otras/ os). Sin embargo, demandan mayor atención de parte de investigadoras/es no-indígenas desde un enfoque no solo epistemológico u ontológico sino político. Este artículo observa las relaciones sensoriales, espirituales, territoriales y eróticas entre cuerpos de la Mapu en El Shumpall (2014). Analizo la representación de un imaginado espacio de "buen vivir" (kïme az mogen), el cual traducido a la tradición literaria occidental equivaldría a un locus amoenus. Esta poética dialoga con las luchas por las "recuperaciones territoriales" en la Mapu williche-lafkenche.

Palabras clave: Territorio, cuerpos, "eroticidad" de la Mapu.

Abstract: The relations between human and nonhuman lives have been widely approached by Mapuche scholars (Calfío, Curivil, Pichinao, among others). However, they demand greater attention from non-indigenous researchers not only from an epistemological or ontological focus but a political one. This paper addresses the sensory, spiritual, territorial and erotic relationships between bodies of the Mapu in El Shumpall (2014). I analyze the representation of an imagined space of "good living", which in the Western literary tradition would be equivalent to a locus amoenus. This poetics, I argue, dialogues with the struggles for the "territorial recoveries" in the williche-lafkenche Mapu.

Key words: Territory, bodies, "eroticity" of the Mapu.

Recibido: 10/06/2019

Aceptado: 09/09/2019

1 Este artículo es una versión abreviada de un texto que incluye el poemario Shumpall de la misma autora. El trabajo se enmarca en un proyecto de tesis doctoral en desarrollo. Quisiera agradecer a Luis Cárcamo-Huechante, Kelly McDonough y Jorge Pérez por sus cuidadas lecturas y generosos comentarios. 
Küme az, mogen, en lengua Mapuche o mapudungun, significa "buen vivir". Es un concepto fundamental para el ethos de las y los Mapuche, que corresponde a un co-habitar la Mapu, Tierra, en conexión corporal y espiritual con ésta, junto a todos los seres humanos y no humanos en ella (Pichinao 95-103). La obra El Shumpall (Jauría Films, 2014) dirigida por Gerardo Quezada Richards, producida por la poeta Mapuche Roxana Miranda Rupailaf y basada en su tercer poemario Shumpall (Del Aire, 2011), invita a una exploración del küme az mogen en cuadros poéticos donde el cuerpo de una domo o mujer Mapuche, un shumpall u hombre-pez y los cuerpos del territorio que habitan se afectan y (con)funden sensorial y espiritualmente. ${ }^{2}$ Sin embargo, el küme az mogen o buen vivir ha sido amenazado y destruido reiteradas veces en el Wallmapu, territorio Mapuche, a través de la historia colonial y sus continuidades. ${ }^{3}$ Durante más de cinco siglos, no solo se han ocupado terrenos expoliados a las comunidades de diversas maneras, sino que las prácticas mercantiles y extractivistas deterioran el medio ambiente y la vida misma (Chihuailaf 53-54; Pichinao 92-95). En Chile, tras la imposición del régimen neoliberal durante la dictadura de Augusto Pinochet (1973-1990), latifundistas criollos, empresas forestales e hidroeléctricas, han dificultado y en varias ocasiones hecho imposible la salud física y espiritual de la Mapu y sus habitantes.

Este quebranto de la vida Mapuche es la manifestación contemporánea de un largo proceso de "violencia colonial", descrita por la Comunidad de Historia Mapuche como "una agresión de carácter sistemática y masiva. . . [que] se materializa por la vía de los cuerpos, gente, seres, máquinas y objetos colonizadores" (Antileo et al. 15). En este contexto, algunas comunidades Mapuche o lof se proclaman autónomas del Estado y realizan "recuperaciones territoriales", es decir, asentamientos en tierras expoliadas (Llaitul 357).4 Para estas personas, recuperar la Mapu, la tierra en su sentido más amplio, “donde se incluyen las aguas, el aire, los seres vivos y muertos, los animales, los espacios naturales y urbanos, la lengua, la esfera

2 El cortometraje El Shumpall está disponible online de forma abierta en Vimeo.com. Miranda Rupailaf considera al video como una obra colectiva realizada entre amistades como Gerardo Quezada a cargo de la dirección y fotografía, Patricio Curihual en la dirección de arte, Faumelisa Manquepillán a cargo de la música y Ximena Huilipan quien interpretó a la mujer Mapuche (Entrevista personal).

3 La palabra Wallmapu fue utilizada a fines de los 80-principios de los 90 para reivindicar el territorio previo a las invasiones chilena y argentina y traer al presente la capacidad de auto-determinación y auto-gobierno de la gente Mapuche (Cárcamo-Huechante, "Mapuche Historians" s.p.). Según el historiador Pablo Marimán, el Wallmapu abarcaba desde el río Copiapó a la isla de Chiloé, por su lado oeste, y del río Quinto a la actual provincia de Chubut, por su lado este, aproximadamente (54-77), previo a invasiones de los ejércitos chileno y argentino en la segunda mitad del siglo XIX.

4 Las recuperaciones son consideradas ilegales por las leyes chilenas en base a los derechos propietarios. Fuerzas especiales del Estado, amparadas por la ley Antiterrorista, realizan desalojos con exacerbada violencia, que ha sido criticada en reportes especiales del Human Rights Council de la ONU en los años 2004, 2009 y 2013 (Anaya; Emmerson). 
psíquica y espiritual, la vida Mapuche en su conjunto" (Antileo et al. 16), se vuelve una urgencia que no solo proviene de la pérdida y el dolor, sino de una pulsión por vivir.

En las costuras de este tapiz de prolongadas violencias coloniales que cubre y daña el territorio histórico o Wallmapu, Roxana Miranda Rupailaf dibuja un diseño que contesta el ultraje. En este artículo concibo la obra audiovisual El Shumpall como una lírica y política "recuperación territorial" que imagina una vida Mapuche centrada en las sensibilidades somáticas de la Tierra y sus vidas. El video registra lo que llamo "eroticidad" de la $M a p u$, un entramado de sensaciones, intenciones y roces entre cuerpos y fenómenos que conforman un lugar. La eroticidad resuena en lo que Kathleen Stewart sugiere sobre los afectos al decir que éstos constituyen una maraña de trayectorias, conexiones y disyunciones de cierta intensidad y textura (4). El video-poema transmite una plasticidad del eros que fluye por las superficies y anima los cuerpos del territorio. La eroticidad de la Mapu es experimentada como medioambiente y, a la vez, como un ímpetu de vida y muerte. La obra constituye un canto a la procreación del mismo lugar y ethos Mapuche, una visión que contrasta y desafía la brutalidad del orden colonial, patriarcal y extractivista largamente impuesto sobre la Tierra y sus vidas. ${ }^{5}$

Miranda Rupailaf ha publicado a la fecha cuatro poemarios, Las tentaciones de Eva (2003), Seducción de los venenos (2008), Shumpall (2011) y Trewa Ko (2018), y es reconocida como una de las voces más interesantes de la poesía de inicios del siglo veintiuno en el Wallmapu y Chile. Su biografía está entrelazada con la "identidad territorial" que se representa en El Shumpall. El video-poema se sitúa en un entorno natural que es parte del Lafken Mapu, la tierra costera del Wallmapu, en este caso, parte o fronteriza con el Willi Mapu, tierra del sur. Miranda Rupailaf creció en la localidad San Juan de la Costa del Lafken Mapu y ha pasado gran parte de su vida en la ciudad willliche Chaurakawin, llamada Osorno por los colonos, ubicada a unas tres horas del océano Pacífico. Su escritura del poemario Shumpall se inspira en los relatos que escuchó habitando la localidad costera de Niebla (Miranda Rupailaf, "Me quitaron" s.p.; entrevista personal). Los y las shumpall son seres vivos que protagonizan un antiguo relato oral o nütram del cotidiano lafkenche. ${ }^{6}$ Existen diversas versiones de este pero, en general, todos relatan el encantamiento y rapto de una joven mujer a orillas del mar por un shumpall. La adolescente es llevada a vivir a las profundidades del océano para formar una familia, pasando a ser ella misma una

5 El erotismo es una temática presente en diversas obras Mapuche. Sin embargo, una lectura desde la "eroticidad" que integra al medioambiente y conecta los cuerpos desafiando la sensualidad y sexualidad del orden colonial, es parte de mi propuesta de tesis doctoral en desarrollo.

6 Los nütram son un tipo de discurso original del mapudungun que consiste en una narración realizada en el contexto de una conversación, que puede tratar diversos temas, desde aspectos de la cultura, la historia Mapuche hasta eventos de la vida diaria (Catrileo 65). 
mujer-pez (Colipan s.p.). En su nueva forma, esta visita su antiguo hogar para dar aviso del pago por su rapto, siguiendo las normas sociales del ngapitun, el secuestro (o simulacro de secuestro) de una mujer por un hombre para hacerla su esposa (Llamin 41). Los familiares acuden a la playa donde grandes olas botan peces, mariscos y algas en retribución (Llamin 101-106).

Como ser hipnótico capaz de enamorar y realizar un ngapitun, la figura del shumpall permite a Miranda Rupailaf exponer el eros poético-político del az mogen, la vida Mapuche, realzando la íntima convivencia del ser humano con cuerpos "encantados" de la Mapu. El video-poema gira en torno a los afectos entre unos cuerpos y otros, entendiendo por esto "la incidencia o transgresión de un momentáneo o, a veces, sostenido estado-de-relación, así como el transcurso (y su duración) de fuerzas o intensidades"7 (Seigworht y Gregg 1). Estas intensidades en el cortometraje surgen de un repertorio de placeres somáticos, una vehemencia del deseo erótico y una (con)fusión de los cuerpos. Sus trayectorias están imbuidas en las siluetas y los contornos, las formas y texturas del territorio.

La Mapu llama a descifrarla desde una observación sensorio-imaginativa, por esto, como metodología transversal ejercito una lectura descriptiva siguiendo a Heather Love, Sharon Marcus y Stephen Best, quienes afirman que la descripción nos permite ver más, mirar con mayor atención y de forma más selectiva (14). Además, ésta facilita el salirnos de nosotras/os mismas/os para conectarnos con aquello descrito, sus creadoras/es y otras descriptoras/es (14). A su vez, Love, Marcus y Best defienden una "lectura de superficies" porque el acto de describir y las descripciones mismas son capaces de producir placer en su lento apreciar (14).

En consecuencia, en este artículo miro, escucho y palpo las superficies del texto audiovisual, sus naturalezas corpóreas, en busca de las historias y experiencias grabadas — tatuadas, marcadas - en ellas. La estilizada estética del entorno en el video-poema constituye al territorio como un locus amoenus Mapuche, un lugar idóneo para el küme az mogen o buen vivir, donde se experimenta la eroticidad. El deseo erótico entre la mujer y el shumpall se constituye como una fuerza generadora del ethos Mapuche. Así, la obra, en las antípodas de la histórica y prevalente destrucción de la Mapu, exhibe escenas de la procreación cíclica del territorio Mapuche y posibilita su buen vivir. La siempre vigente existencia de este ethos aún si es en malas condiciones, constituye el sustento espiritual de las comunidades actualmente en procesos de recuperación territorial.

7 La traducción es mía. 


\section{El lugar del küme az mogen}

Una mujer con vestido ligero hasta las rodillas camina tranquila de espaldas por una colina natural hacia un horizonte de cielo. Es un plano general. La imagen está drásticamente dividida en oscuridady luz: en la parte inferior del encuadre, la tierra y la mujer sombreadas; en la parte media y superior, nubes blancas esponjosas se mueven lentamente. El terreno se adivina suave por el caminar descalzo. En la linea de contorno se dibuja la silueta de una vegetación de duna baja, desordenada, que se suma a la cabellera de la mujer en sus texturas fibrosas. Varios sonidos crean una atmósfera hipnótica. Un constante rumor líquido y los cantos de las aves costeras anticipan la imagen robusta del mar y su espuma. Suena fuerte el sonido del trompe haciendo notas vibrantes de cortas ondas sucesivas que rebotan sobre sí mismas y en el aire (El Shumpall 0:00-0:47).

Este inicio del cortometraje El Shumpall marca la sensorialidad del video-poema

y la vinculación de la domo con el territorio. El océano, a través de su movimiento ondulante y sus matices de azul, es un centro magnético que llama a la domo a cruzar la silueta-umbral de las dunas. Visualmente, el cruce simboliza las diferentes dimensiones de la Mapu. La Wenu Mapu, la Tierra de Arriba, es el lugar de los astros y de los "seres y espacios que forman parte del conocimiento cosmológico y/o ontológico" Mapuche (Canio y Pozo 14). Es, también, el lugar donde continua la vida humana después de la muerte, pero no en el sentido del "más allá” judeo-cristiano (Curivil 38), pues la Wenu Mapu ejerce su influencia sobre las vidas de la Nag Mapu, la superficie terrestre, donde habitan las personas humanas, vegetales y animales (Canio y Pozo 14-15). La Mince Mapu, la Tierra de Abajo, es el lugar de la vida mineral y de las aguas subterráneas (Curivil 37-38), asimismo de los espíritus negativos (Chihuailaf 30). La figura de la domo es representada en armonía con estas tres capas de la Mapu. Ella camina apaciblemente por la Nag Mapu, y, a la vez, los cambios de iluminación insinúan su habitar simultáneo en los otros espacios: se la ve tanto oscurecida por las sombras de la Mince Mapu, como resplandeciente de luz por la presencia de la Wenu Mapu. En el pensamiento Mapuche, según Ramón Curivil, "la división sagrado-profano, material e inmaterial, en la práctica no es tan real, dado que la vida finalmente se juega en ambos espacios" (38). Así, el habitar de la domo transcurre en confluencia con las dimensiones espirituales y físicas de la Tierra, por esto, más de una vez se la muestra caminando por la línea horizontal que divide y, al mismo tiempo, une la tierra y el cielo o la tierra y el mar.

La corporalidad "individual" de la mujer es relativizada en las imágenes, enfatizando su familiaridad con todas las vidas y cuerpos del entorno. La domo es presentada como hija de la madre tierra o Mapu Ñuke en planos generales que la muestran como un elemento más del paisaje. La vemos a lo lejos, borrosa, o bien de espaldas sin una cara que la personalice, o solo se nos muestra la parte inferior de sus pier- 
nas y pies en continuidad con la duna. No existe una jerarquía que la ubique por encima de otras naturalezas corpóreas. En una escena en particular, la sombra de la domo deambulando se fusiona con un gran árbol. El claroscuro no responde a la interpretación clásica de su uso en el cine, según la cual los personajes horrorosos o misteriosos permanecen en la oscuridad (Bordwell y Thompson 182). Al contrario, cuando la domo es sombría destaca su pertenencia a la Mapu en igualdad de condiciones con los demás seres con que cohabita. Como indica la palabra "Mapuche", gente de la tierra, las personas pertenecen a la Tierra y no al revés: "Es más que ser originario del lugar — explica Curivil— es haber nacido del mapu y ser parte del mapu a la vez" (31). Este az mogen, forma de vida, se diferencia del pensamiento moderno patriarcal que otorga a los "hombres" (en representación de la humanidad) una condición de excepcionalidad, ubicándolos como "especie" por sobre todos los otros seres de la naturaleza (Pisano 33). La deshumanización de la domo, por tanto, desestabiliza el orden colonial masculino.

El equilibrio entre la domo y las dimensiones de la Tierra, junto a la familiaridad de los seres de la Mapu Nuke crean un ambiente de mutuo cuidado propicio para el placer, un locus amoenus. El video-poema muestra superficies suaves, sedosas y blandas: la duna, la pradera, la playa, el mar, el cielo y las nubes. A su vez, se exhiben suelos rocosos, duros y toscos como invitantes miradores y bellos parajes. Este contraste de lo suave y lo áspero invita al despertar de los sentidos, a sentir con la imaginación el contacto de la domo con el medioambiente. Los encuadres bucólicos refuerzan la idea de un lugar ameno con su calidez y luminosidad de tonos pasteles - amarillos, dorados, cafés y verdes. Por otra parte, el mar y su entorno inmediato de pigmentos intensos y cambiantes codifican la naturaleza animada de las aguas, indicando la presencia y energía del shumpall, la fuerza que afecta a la domo y que, a su vez, es afectado por ella.

La sensual visualidad de este espacio de "buen vivir" o küme az mogen, suerte de locus amoenus en clave occidental, se complementa con los sonidos del entorno: el video crea un ambiente vivo donde todo reverbera y emana: el canto de pájaros silvestres, el viento entre los árboles, el trascurrir del agua de vertiente, el trinar de las aves costeras y el predominante vaivén, a veces intenso, otras suave, del ondular de las olas. ${ }^{8}$ El compositor Michael Chion en su teorización sobre la "audio-visión", afirma que a este tipo de sonidos se les puede llamar "territoriales" pues sirven para identificar un lugar en particular, a través de su presencia ubicua, penetrante y continua (75). Su afirmación es precisa en este registro, ya que El Shumpall produce

8 El locus amoenus es un tópico literario que se usa para identificar caracterizaciones de lugares apacibles, generalmente, en entornos naturales. Tiene una larga historia, que se puede rastrear hasta Homero, pero fue en la época del Renacimiento en Europa que se revitalizó su uso. En este artículo, utilizo el tópico para subrayar la idea de que el registro audiovisual presenta un lugar apacible, apto para la vida buena. 
la sensación de un solo cuerpo, la Mapu, conteniendo muchos seres en un "fluir sónico” (45), al decir de Chion.

En el video-poema, entonces, se construye un continum sensorial: un solapamiento de imágenes y sonidos que buscan despertar los sentidos, más que transmitir ideas pre-codificadas por el lenguaje (Chion 154). Así, las palabras en mapudungun anunciadas por una voz en off, su cadencia, pronunciación y entonación, se funden con los ruidos territoriales. Esta voz representa el rumear de la conciencia de la domo, su intimidad acoplada a la vitalidad ruidosa del lugar. Luis E. Cárcamo-Huechante afirma que el mapudungun "al identificar al lenguaje con la tierra, se sale de la lógica antropocéntrica y expresa un territorio de resonancias vastas y múltiples: es la fonética de un universo poblado por seres que susurran, murmuran, hablan, gritan, sollozan o cantan" (228). En este sentido, el mapudungun en el video aporta a la representación sonora del icrofil mogen, la biodiversidad y la biosfera a la que pertenecen los seres humanos, compuesta de cuerpos vivos y saludables (Chihuailaf 52). Los sonidos territoriales y el mapudungun en la obra enfatizan la diversidad de seres que cohabitan en este gozoso y familiar locus amoenus. Como describe Chion sobre el continum sensorial, los ruidos ambientales introducen un sentir agudo de la materialidad de las cosas y los seres (155), en este caso introducen también un ritmo pausado que denota intimidad y pertenencia.

Los paisajes audiovisuales de El Shumpall despiertan, por tanto, la memoria histórica, medioambiental y familiar del lugar como territorio Mapuche. El video-poema fue grabado en las localidades rurales y costeras de Chaihuín y Curiñanco, Provincia de Valdivia. En la captura de sus parajes hay un llamado implícito a reconocerlas como parte de la Mapu Mapuche, pues los encuadres dejan fuera las huellas visuales y sonoras de la continuidad colonial. Es un retrato poético de los territorios: las cámaras fusionan los paisajes de Chaihuín y Curiñanco y crean un solo lugar, un Edén Mapuche dedicado al küme az mogen, el buen vivir. Pero también es un registro político del Lafken Mapu, porque invita a pensarlo como un lugar placentero y saludable que contrasta con la realidad enferma de muchos lugares del Wallmapu por el asentamiento urbano e industrial de los colonos. Más aún, el cortometraje insinúa un futuro posible: la recuperación del habitar Mapuche libre y vigoroso en estos territorios. ${ }^{9}$

9 Se piensa que el contacto de los lof Mapuche que habitan esta zona con la sociedad colonial fue tardío, debido a que a mediados del dieciocho la concentración indígena seguía siendo predominante (González 310). Luego de la invasión militar chilena (1860-1883), la población original se redujo por enfermedades introducidas y por la ocupación a manos de colonos españoles, criollos chilenos y alemanes (Correa s.p.). Los lof fueron desarticulados y reorganizados en reducciones territoriales y, más tarde, en 1979, durante la dictadura, éstas fueron subdivididas en lotes individuales por el Decreto Ley 2.568. Actualmente, en Curiñanco, desde el año 2017, existe un lof en recuperación territorial llamado Reivindicación Narciso Ñanco (Lof Narciso Nanco s.p.) y es posible encontrar personas hablantes del mapudungun. En contraste, 
En consecuencia, el video-poema, a través de la puesta en escena de este locus amoenus particular, crea un lugar-hogar Mapuche. La única edificación humana que se muestra es la ruka, la casa de la domo, representando el núcleo físico de un hogar que se expande más allá de sus paredes. El mapudungun tiene significantes específicos que emparentan la tierra con las personas: el küpalme y el tuwün, conceptos que, según Chihuailaf, son los cimientos de las comunidades (50). El küpalme refiere a la unión sanguínea, recordando que todas las personas son hijas de la Mapu en primer lugar (Chihuailaf 51). El tuwün "es el fundamento básico de la familia, anclado en el espacio físico en el cual ha nacido, crecido y se ha desarrollado la gente" (Chihuailaf 51). Las y los Mapuche unidas/os por la materia corpórea del küpalme, también se vinculan por y con su tuwün, su territorio. El hogar, entonces, en el ethos Mapuche refiere a algo más que la ruka, incluye el lugar de origen y acoge a una familia amplia de diversas vidas y cuerpos. El küme az mogen se desarrolla en las relaciones entre el küpalme y el tuwün, en las relaciones de parentesco entre las personas humanas, el lugar y sus otros habitantes.

El lugar del küme az mogen contiene una atmósfera hogareña, de protección, que se expande por todo el territorio abriendo paso a la ensoñación y la exploración de las emociones. Por medio de la voz (en off) de la domo asistimos a la oscilación y exacerbación de sus sentimientos. Afectada profundamente por el mar, su amor es lafkenche pues el océano es la marca prominente de esta identidad territorial: de él depende la vida y muerte de las personas que viven en sus cercanías. Miranda Rupailaf ha comentado la poderosa presencia del mar en su vida, recordando que rupailaf significa camino de mar (Entrevista personal). Su nombre evidencia el küpalme y el tuwün al que pertenece. Así, el hogar de la poeta es integrado al video-poema en clave amorosa: entre la domo y el shumpall se establece una relación de amantes, augurada desde un comienzo por los ritmos del trompe, el sonido del romanceo, dicen sus cultores ("El trompe" s.p.). Este amorío de intenso erotismo exacerba el küme az mogen del territorio costero, realzando los placeres del encuentro físico y espiritual de la Mapu, como una fuerza regeneradora, de vida y muerte, que circula por todo el entorno.

\section{El newen erótico de la Mapu}

"Voy a hundirme en esta ola que es tu nombre", declara la voz interior de la domo en mapudungun. Y repite: "Voy a hundirme en esta ola que es tu nombre - te dije-

la mayoría de los habitantes de Chaihuín se identifica con el estilo de vida criollo. Hubo un intento de revitalizar el ethos Mapuche con el "Encuentro de Poesía" Mapuche y no-Mapuche, organizado anualmente desde el 2007 al 2009 por el centro cultural Kaykayen, al que perteneció Miranda Rupailaf (Centro Cultural s.p.). 
/y nos llenamos, desbordados, atorados de luciérnagas". ${ }^{10}$ La continuidad entre el placer sensorial del locus amoenus y la exacerbación del deseo de la domo se concentra en la palabra "hundirme". Así como los pies de la domo penetran la suave duna, su alma se interna en la inmensidad alborotada del océano. En la voluntad de hundirse, la ola revela toda su capacidad sensual: abraza el cuerpo de la hablante, la empapa, la acaricia, la excita. La mujer y su amante, en estos versos, se desbordan de luces fosforescentes, brillo que grita una liberación física y espiritual. La voz de la domo es poesía ansiosa de unión carnal, que crea imágenes eróticas con elementos de su tuwün lafquenche.

La potencia de este deseo es presentada en el cortometraje como newen, fuerza vital de la Mapu Mapuche en su condición de tierra "sagrada" y "misteriosa" (Curivil 37). En el video se observa una energía ubicua que se dispersa por todo el territorio y anima sus diversos cuerpos. En este sentido, el concepto "trans-corporealidad" de Stacy Alaimo resuena con la obra pues propone que "lo humano está siempre enredado con el mundo-más-que-humano" (2). El prefijo "trans" hace énfasis en el intercambio y las interconexiones de múltiples naturalezas corpóreas que transitan y convergen en un espacio móvil (2). En el video, la eroticidad de la Mapu se vive como el medioambiente, como una segunda atmósfera terrestre dentro de la cual todo se conecta. La figura del shumpall enfatiza la permeabilidad o ilusión de los límites corporales, pues el hombre-pez es un ghe, ser protector del espacio (Curivil 37), que como tal se (con)funde con el territorio. De esta manera, aunque solo lo vemos dos veces en la segunda mitad de la grabación, su newen erótico se manifiesta en los seres de la Mapu. Planos enteros de lobos marinos recostados unos sobre otros, con la belleza de sus pieles brillantes, húmedas, flexibles y robustas en fricción, insinúan una voluntad de contacto físico entre cuerpos, el placer de tocarse. A su vez, primeros planos de tupidas algas flotando en el agua, al ritmo de sinuosas ondas de lento movimiento, sugieren el goce de la deriva, el dejarse llevar por las pulsiones psico-físicas y la intención del shumpall de seducir a la domo y enredarla en sus cabellos.

La génesis de las personas-pez se relaciona con una fuerza, newen, regeneradora de la vida Mapuche. Según el nütram (relato) del poeta Bernardo Colipán, la figura de los y las shumpall surge del epew (antigua narración) de Kay-Kay y Tren-Tren, que enseña sobre el resurgimiento del mundo Mapuche. La serpiente Kay-Kay subió el nivel de las aguas de la Mapu y Tren-Tren elevó la Tierra para salvar a las/os Mapuche, pero las personas que no lograron escapar de las olas se convirtieron en "lobos marinos, peces y shumpales. . . [que] siguen viviendo en su estado humano en el fondo del mar, ríos y lagos" (Colipán s.p.). De la catástrofe sobreviven una

10 El cortometraje contiene subtítulos en español de los versos en mapudungun, que corresponden a extractos del poemario. 
pareja de ancianos y una de jóvenes, estos últimos repueblan la Mapu (Chihuailaf 202). Por tanto, las y los shumpall participan de una potencia revitalizadora del mundo Mapuche como seres capaces de transitar de una vida a otra, transformando su corporalidad. ${ }^{11}$

El newen erótico, como fuerza renovadora del ethos Mapuche, es un fenómeno sagrado. La domo traduce su deseo a los códigos de la rogativa y ritualiza su afán en el templo sacro de su locus amoenus. Por esto, ella viste de negro, el color del küpam, paño con que las mujeres Mapuche envuelven sus cuerpos, en especial cuando hay ceremonia. En mitad del cortometraje, ella completa un atuendo formal usando sus alhajas de plata: el trarilonko, cintillo, y la trapelakucha, pechera. Así, la vemos esparcir semillas alrededor de un joven árbol que pudiera ser el foye, canelo, árbol sagrado y, luego, bañarse en el mar. Los versos recitados en mapudungun, acompañan sus acciones:

Repito este mi rezo

por si vienes.

Aquí frente a las olas me arrodillo.

Yo invoco tus cabellos anudados por la sal.

La mujer ruega por la aparición del ser divino, por la materialización antropomorfa de un ambiente cargado de anhelo. En respuesta, la agencia erótica de la Tierra hace posible el encuentro por medio del perimontun o visión, que consiste en la aparición de seres sobrenaturales, generalmente, en los peuma o sueños de las personas humanas (Curivil 39-40). Así, la unión de los cuerpos de la domo y el shumpall, en la forma del mar, sucede cuando ella está dormida.

Una luna llena, color amarillo tibio, se ubica al centro de un cielo negro. El movimiento del aire desdibuja levemente sus contornos. Un plano entero semi-frontal exhibe a la domo dormida en su cama. Su expresión facial es de profundo placer. La silueta de una chailla, olla, cuelga sobre lo que se adiva el kutral, fogón, por la humareda que sube delicadamente. La luz del fuego ilumina a la domo de frente, resalta sus facciones, sus labios y pechos. El ritmo repetitivo del kultrun, timbal de madera y cuero, más el sonido del mapudungun y la sinuosidad del humo y la luzproducen una sensación de conciencia en trance (5:56-6:03).

La escena descrita prepara el camino a las imágenes del perimontun. La luna o küyen anticipa el ritual de unión física en su rol de madre de la Wenu Mapu, que permite

11 Miranda Rupailaf supo de la existencia de los y las shumpall cuando estaba escribiendo su tercer poemario en la localidad costera de Niebla, cercana a Chaihuín y Curiñanco. Al compartir los versos con otras personas Mapuche, éstas le indicaron que estaba describiendo la fuerza de un shumpall, un ser que no es legendario, sino que cohabita la cotidianeidad en la costa (Entrevista personal). 
la vida y la procreación (Canio y Pozo 56-57). La ruka, casa, con sus elementos de la cotidianidad Mapuche, es el escenario apto para el encuentro de la pareja edénica de este locus amoenus. El kutral, fogón, anticipa la pasión y el calor corporal. A su vez, el humo es un indicio del habitar de la domo en otra dimensión.

La unión de los amantes en el trance del perimontun representa la renovación de las energías de la Mapu, su resurgimiento, como en el epew de Kay-Kay y Tren-Tren. El sonido del kultrun acompaña los latidos y la respiración de la domo en un ritmo ascendente. Este instrumento personal es creado para cada machi (Pérez de Arce, 149), sanadoras y sanadores que hacen de puente espiritual entre las diferentes capas de la Mapu (Chihuailaf 77). El kultrun representa al universo Mapuche o el Meli Witran Mapu, los cuatro lados de la Tierra que dan origen a las identidades territoriales (Chuhuailaf 36-37). Su sonido indica ceremonia, rito, y actúa sobre las personas (Pérez de Arce, 149-154). En el video, las percusiones persistentes marcan el pulso del newen, fuerza, que emana de la unión de los amantes y revitaliza el ethos de la Mapu.

La secuencia del encuentro se visualiza con un montaje alternado entre la domo durmiendo y la domo en el agua. Este tipo de edición usualmente se usa para captar la atención del espectador y motivar una interpretación de la alternancia (Bordwell y Thompson 279-390). En el video-poema, el montaje refiere a la simultaneidad de los sucesos y la ubicuidad de la domo en ambos lugares. Por ende, este entrelazamiento sugiere una experiencia erótica sobrenatural y, en el contexto cultural Mapuche, sagrada. En las tomas que muestran a la domo en su lecho, ella se mueve excitada. Su cara está sudada, sus piernas destapadas y una mano busca tocarse entremedio. En las escenas en el agua, planos "nadir" la captan de abajo hacia arriba nadando por un mar verde-claro, representando la mirada subjetiva del shumpall: él es la profundidad de las aguas, es por su materialidad en estado líquido que atraviesa la domo. La luz brillante que ilumina las escenas representa la confluencia de los cuerpos como una experiencia generadora de energía. Las tomas son cortas, creando un ritmo acelerado.

Por otro lado, el perimontun se constituye como la ceremonia donde la domo se arroja al mar en ofrenda. En esta parte del cortometraje se registra un oxímoron entre imágenes y palabras: mientras las primeras subrayan la vida a través de las tomas de la domo en el agua, los versos recitados erotizan un deseo de muerte:

Y espero a que aparezcas en la tercera ola niño-pez.

Que me trague el mar.

Que me lleven desnuda por la espuma. 
Desde el saber occidental, esta dualidad alude a los principios eros y thanatos del psicoanálisis freudiano, pero en el deseo de la domo está en función la experiencia Mapuche: una memoria afectiva lafkenche de amor y muerte respecto al mar. El mar es el espacio sagrado que aporta el sustento alimenticio de las familias de la costa, que les otorga vida. A la vez, el mar representa la posibilidad de la corrupción de los cuerpos humanos que son "tragados" por sus aguas — pescadores, mariscadores, nadadores, buscadores de shumpall. Así, el negro de la vestimenta de la mujer sugiere un ritual mortuorio, pues su actitud lasciva responde a unas ganas de vivir en el fondo del océano como una shumpall, para lo cual necesita morir como humana.

En consecuencia, la versión del relato del shumpall de Miranda Rupailaf descentra el deseo masculino patriarcal y lo reemplaza con una vehemencia febril de la domo. Si la mujer es raptada en la estructura tradicional del nütram, en el cortometraje el sacrificio es invocado. Hay una preparación y una espera, no del rapto sino del encuentro. Si bien el hombre-pez ejerce sus capacidades hipnóticas, la narrativa del video gira en torno a la rogativa de la domo. Su actitud es la de quien ha vivido el éxtasis y busca repetirlo. Finalmente, ella lo cumple. En la última escena se la muestra sumergida en el agua desde la mirada del shumpall (plano nadir). No es exactamente un cuerpo sin vida sino suspendido, sugiriendo un umbral — "la puerta de este cielo", como dice la voz en off — tras el cual pasará a un nuevo estado. El cierre del video-poema se une con su inicio: la figura sombreada de la domo anticipa su capacidad de transformación en otra corporalidad. Por tanto, el amor erótico de vida y muerte entre el shumpally la domo, un amor queer en cuento transgrede los límites del "especismo", es newen que mueve las energías y los cuerpos de la Mapu, actualiza sus rituales y espiritualidad, permite sus transformaciones. Este ciclo es símbolo de regeneración, de sanación: una recuperación del territorio, su vuelta al küme az mogen gracias a la eroticidad de la Mapu fluyendo en todas sus naturalezas corpóreas.

\section{Reflexiones finales}

La obra El Shumpall, basada en el poemario Shumpall de Roxana Miranda Rupailaf, permite a su audiencia asomarse a la compleja visión de mundo contenida en la Mapu, la Tierra Mapuche. En este artículo he planteado que el video-poema apela a lo sensorio y lo emocional para representar las intensidades de la eroticidad de la Mapu, que permiten el küme az mogen, la vida buena, y el newen, la fuerza que da vitalidad al habitar Mapuche. Mi intención ha sido indicar que esta obra poética-política de bienestar pone de manifiesto, por contraste, la historia de violencias coloniales vivida por el pueblo Mapuche. Existe un diálogo implícito entre las comunidades o lof que hoy están practicando recuperaciones territoriales y las relaciones afectivas entre las diversas vidas de la Mapu en el video. El amor y el arrojo necesarios para recuperar un territorio se alimenta de un ethos de continui- 
dad corporal y una unión espiritual con la Mapu y sus brotes. Solo de esta forma se renuevan sus energías. El Shumpall ilumina la poética implícita en el acto político de la recuperación territorial.

El eros ubicuo trans-corporal que recorre los cuerpos del Lafken Mapu crea un lugar-hogar al infundir de afectaciones y afectos al territorio. Así, el küme az mogen es conciencia del co-habitar en red. Este entramado de energías se erige como un mapa del territorio lafkenche que desconoce los límites impuestos por las demarcaciones geopolíticas de Chile. Además, los versos de Miranda Rupailaf crean una versión del nütram del shumpall donde la mujer tiene voluntad y agencia, por tanto, en esto la poética de la obra es, también, descolonizante. Así, el cortometraje robustece el archivo de la historia Mapuche y, especialmente, activa las sensorialidades y emociones, la complejidad espiritual que mueve al movimiento político por "recuperar" el territorio, la Mapu. Queda por reconocer, entonces, otros puntos poéticos de esta cartografía vibrante, obras de arte y experiencias de vidas que registren diversos afanes, deseos e impulsos del presente y futuro del habitar Mapuche. 


\section{Obras citadas}

Alaimo, Stacy. Bodily Natures: Science, Environment, and the Material Self. Indiana University Press, 2010.

Anaya, James. "Informe del Relator Especial sobre la situación de los derechos humanos y las libertades fundamentales de los indígenas". Consejo de Derechos Humanos Asamblea General de la Organización de las Naciones Unidas. $12^{\circ}$ periodo de sesiones. 5 oct. 2009 .

Antileo, Enrique et al. "Awükan ka kixankan zugu. Kiñeke rakizuam". Awukan ka kaxankan zugu wajmapu mew. Violencias coloniales en Wajmapu, editado por Enrique Antileo, Luis E. Cárcamo-Huechante, Margarita Calfío y Herson Huinca-Puitrin, Ediciones Comunidad de Historia Mapuche, 2015, pp. 9-20.

Best, David, et al. "Building a better description”. Representations, vol. 135, no. 1, 2016, pp.1-21.

Bordwell, David y Kristin Thompson. Film Art. An Introduction. McGraw Hill, 1997.

Canio, Margarita, y Gabriel Pozo. Wenu Mapu. Astronomía y Cosmología Mapuche. Ocho Libros, 2015.

Cárcamo-Huechante, Luis E. "Las trizaduras del canto Mapuche: lenguaje, territorio y colonialismo Acústico en la poesía de Leonel Lienlaf”. Revista de Crítica Literaria Latinoamericana, Año 40, no. 79, 2014, pp. 227-242.

. "Mapuche Historians Write and Talk Back: Background and Role of j...Escucha, winka...! Cuatro ensayos sobre Historia Nacional Mapuche y un epílogo sobre el futuro (2006)". Decolonial Gesture, vol. 11, no.1, 2014.

Catrileo. María. “Tipos de discurso y texto en Mapudungun”. Actas de Lengua y Literatura Mapuche, Vol. 5, 1992, pp. 63-70. Centro Cultural y Ambiental Kaykayen. kaykayen.blogia.com. Accedido 20 mar 2018.

Chihuailaf, Elicura. Recado confidencial a los chilenos. LOM, 1999.

Chion, Michel. Audio-vision: Sound on the Screen. Columbia University Press, 1994.

Colipán, Bernardo. "Qué hay más allá de la tercera ola”. Letras.mysite.com. Web. 29 Oct. 2017.

Curivil, Ramón. La fuerza de la religión de la tierra. Una herencia de nuestros antepasados. Ediciones Universidad Católica Silva Herníquez, 2007.

"El trompe Mapuche de Khano Llaitul". Youtube, subido por TrompeMapuche. Web. 28 Jun. 2013. 
Emmerson, Ben. "Report of the Special Rapporteur on the promotion and protection of human rights and fundamental freedoms while countering terrorism". Human Rights Council, United Nations Organization. Twenty-fifth session. 10 mar 2014.

Llaitul, Héctor. "¡El territorio no se compra, se recupera...! ¿Compra-venta, expropiación control territorial?" Conflictos étnicos, sociales y económicos. Araucanía 1900-2014. Editado por Jorge Pinto, Pehuén, 2015, pp. 353-358.

Llamin, Segundo, et al. Segundo Llamin ñi kuyfike nütram. Las antiguas conversaciones de Segundo Llamin. Ediciones Librería Crisis, 2015.

Lof Narciso Ñanco. "Último comunicado público lof Narciso Ñanco" (24 Mayo 2017)". Territorio Inkieta. Web. 04 Abr. 2018.

Marimán, Pablo. "Los Mapuche antes de la conquista militar chileno-argentina". ¡...Escucha, winka...! Cuatro ensayos de Historia Nacional Mapuche y un epílogo sobre el futuro, editado por Pablo Marimán et al., Lom, 2006, pp. 53-126.

Miranda Rupailaf, Roxana. El Shumpall. Dirigido por Gerardo Quezada, producido por Roxana Miranda Rupailaf, Jauría Films, 2014. Vimeo. 20 Nov. 2017. . Shumpall. Del Aire Editores, 2011.

- "Me quitaron el lenguaje con educación y ahora me exigen que lo sepa". Revista N. 28 Oct. 2013. . Entrevista personal. 2 de diciembre 2017.

Pichinao, Jimena. "La mercantilización del Mapuche Mapu (tierras Mapuche). Hacia la expoliación absoluta”. Awnkan ka kaxankan zugu wajmapu mew. Violencias coloniales en Wajmapu, editado por Enrique Antileo, Luis Cárcamo-Huechante, Margarita Calfío y Herson Huinca-Puitrin, Ediciones Comunidad de Historia Mapuche, 2015, pp. 87-106.

Pisano, Margarita. Los deseos de cambio o... ¿el cambio de los deseos? Editorial Revolucionarias, 2011. 